\title{
Phenylalanine to Tyrosine Ratio Measurement
}

National Cancer Institute

\section{Source}

National Cancer Institute. Phenylalanine to Tyrosine Ratio Measurement. NCI Thesaurus.

Code C81281.

The determination of the ratio of phenylalanine compared to tyrosine present in a sample. The measurement may be expressed as a ratio or percentage. 